\title{
Entre as conexões e as desconexões: experiências acadêmicas em tempos de distanciamento social físico
}

\author{
Among connections and disconnections: academic experiences in times of \\ physical social distancing
}

\author{
Regiane Caldeira \\ Doutora em Sociologia \\ Universidade do Estado de Mato Grosso -UNEMAT. \\ Nova Xavantina, Mato Grosso - Brasil. \\ regianecaldeira@unemat.br \\ Stephanni G. Silva Sudré \\ Mestre em Ciência Ambienteis \\ Universidade Federal do Tocantins -UFT \\ Araguaína, Tocantins - TO . \\ stephanni_@mail.uft.edu.br
}

\author{
iD Gabriel José Pereira \\ Especialista em Docência do Ensino Superior \\ Universidade do Estado de Mato Grosso - UNEMAT. \\ Sinop, Mato Grosso - Brasil. \\ aldeiaturismo@gmail.com
}

Resumo: A presente pesquisa objetiva conhecer formas de comunicação utilizadas pelos estudantes da Universidade do Estado de Mato Grosso - UNEMAT, câmpus Nova Xavantina, a fim de "vencer" o distanciamento físico e verificar como isso impacta no engajamento com o processo de ensinoaprendizagem adotado pela instituição. A pesquisa apresenta caráter exploratório quanto aos seus objetivos, quanti-quali quanto à abordagem do problema e estudo de caso como delineamento. A técnica escolhida para a geração de dados foi o questionário. Os resultados indicam que há um movimento intenso em termos de tentativas de adaptação. Os estudantes, apesar da desenvoltura no que se refere às tecnologias, sentemse confusos, inseguros quanto à sua capacidade de processar tantas informações ao mesmo tempo, sejam elas conteúdos, quanto habilidades que precisam ser desenvolvidas e/ou aprofundadas para terem acesso ao ensino remoto emergencial adotado pela instituição. Ao mesmo tempo, visualizam oportunidades de aprender, de forma mais dinâmica e flexível.

Palavras-chave: Acadêmicos. Ensino remoto emergencial. Ensino superior. Comunicação. UNEMAT.

\begin{abstract}
This research aims to know forms of communication used by students of the Universidade do Estado de Mato Grosso -UNEMAT Nova Xavantina to "overcome" the social distancing and how they can impact the engagement with the teaching-learning process adopted by the institution. The research adopts an exploratory character to its objectives, quantitative and qualitative research to approach the problem, and case study as a design. The technique chosen for data generation was the questionnaire. The results indicate that there is an intense movement in terms of adaptation attempts. Students, despite their resourcefulness regarding technologies, feel confused, insecure about their ability to process so much information at the same time, be it content that must be studied, as well as skills that need to be developed to have access to emergencial remote education. At the same time, they see opportunities to learn in a more dynamic and flexible way.
\end{abstract}

Keywords: Academics. Emergencial remote education. Higher education. Communication. UNEMAT. 
CALDEIRA, Regiane; SUDRÉ, Stephanni G. Silva; PEREIRA, Gabriel José. Entre as conexões e as desconexões: experiências acadêmicas em tempos de distanciamento social físico

\section{Considerações iniciais}

Com a pandemia, variadas estruturas que norteavam as ações dos indivíduos tiveram que ser repensadas, reorganizadas, adaptadas e até excluídas das práticas cabíveis ao momento atual. Dentro desse movimento cheio de incertezas se encontra a educação, pautada em um formato de ensinar e aprender enraizado na presença física, mas com tendências para o não presencial. Diante da proibição das atividades que gerassem aglomerações e a necessidade de afastamento social, as instituições de ensino se viram em uma situação delicada, já que as suas bases não se conectavam mais com a demanda do momento.

Em março de 2020, as atividades letivas são então paralisadas. Diante desse cenário "O Ministério da Educação (MEC) permite a partir da Portaria no 343 de 17 de março de 2020 a substituição das aulas presenciais por aulas em meios digitais, enquanto durar a situação de pandemia da COVID-19”. (BRASIL, 2020, p. 1). O formato de ensino remoto emergencial (ERE) se torna uma das opções ao enfrentamento da pandemia, no que se relaciona à educação. Dentre as instituições de ensino superior, algumas aderiram a resposta dada pelo MEC, outras ainda estudam a sua viabilidade, sem indicativos de retorno às aulas.

Em meio a tantas indagações, encontra-se um público que sente, de forma bastante singular, os impactos da pandemia nas suas vidas: os acadêmicos. A fim de conhecer como estão vivenciando o momento pandêmico via lentes da comunicação, o presente estudo estabeleceu como objetivo geral conhecer as formas de comunicação que estão sendo utilizadas pelos estudantes, a fim de "vencer" o afastamento físico e como podem impactar no engajamento com o processo de ensino-aprendizagem adotado pela Universidade do Estado de Mato Grosso UNEMAT, em formato emergencial. Como objetivos específicos se propõe: identificar as ferramentas de comunicação usadas pelos estudantes antes e durante o período pandêmico; apontar as experiências dos acadêmicos com ensino não presencial; relatar o olhar dos acadêmicos em relação ao ensino não presencial e discutir como as formas de comunicação adotadas pelos estudantes podem influenciar no formato ERE adotado pela UNEMAT.

A fim de atender a fim de atender ao que foi proposto nesta pesquisa, adotou-se um plano de pesquisa de caráter exploratório quanto aos seus objetivos, quanti-quali quanto à abordagem do problema e como delineamento de pesquisa, optou-se pelo estudo de caso. A pesquisa de campo ocorreu de forma virtual, obedecendo as recomendações de distanciamento social indicadas pelos órgãos de saúde nacionais e internacionais.

A técnica escolhida para a geração dos dados foi o questionário. A construção do formulário se deu a partir da ferramenta Google Forms, composta por perguntas abertas e fechadas, 
totalizando 77 questões em 6 sessões, permanecendo aberto a respostas do dia 30 de junho ao dia 15 de julho de 2020. Os compartilhamentos foram realizados primeiramente via e-mail dos acadêmicos, obtidos pela secretaria acadêmica do câmpus UNEMAT Nova Xavantina. Os acadêmicos foram convidados a participar deste estudo de forma voluntária, não sendo identificados em nenhum momento da pesquisa. Além disso, o link para participar foi compartilhado no site do Câmpus UNEMAT Nova Xavantina, Blog do Curso de Turismo, Facebook dos membros da pesquisa, docentes e estudantes do câmpus Nova Xavantina, grupos do Whats $A p p$ de docentes, profissionais técnicos do ensino superior - PTES e acadêmicos, sob a solicitação de divulgação.

A presente pesquisa se desenvolveu no âmbito do projeto de pesquisa "Acadêmicos em tempos pandêmicos: trabalho, alimentação, emoções, comunicação e lazer", institucionalizado pela Pró-reitoria de Pesquisa e Pós-graduação da Universidade do Estado de Mato Grosso.

O câmpus UNEMAT Nova Xavantina possui 1201 acadêmicos matriculados nos cinco cursos ofertados, divididos em termos quantitativos da seguinte maneira: 412 Agronomia, 315 Engenharia Civil, 224 Biologia, 160 Turismo e 90 Direito. Desses universitários, 492 estudantes participaram do presente estudo, assim divididos em termos percentuais: 35,6\% estudantes de Agronomia, 12,6\% de Biologia, 9,1\% de Direito, 31,3\% de Engenharia Civil e 11,6\% de Turismo. A faixa etária dos respondentes variou entre 18 a 42 anos. Do total dos entrevistados $57 \%$ são de gênero feminino e 43\% masculino, as condições sexuais indicadas foram de $88,1 \%$ heterossexuais e 11,9\% homossexual, bissexual, pansexual, assexual e outros.

Apesar do contexto pandêmico ser uma realidade na qual todos estão imersos, as experiências podem se apresentar como bastante diferenciadas. Nesse sentido, leituras a partir de diversos ângulos contribuem para a compreensão do que se passa em ambientes similares e diferentes. Este estudo busca contribuir com a exposição de experiências de acadêmicos de uma universidade estadual, ainda assim, não se trata de algo generalizável, pois os dados partem de apenas um dos seus câmpus.

\section{$2 \mathrm{O}$ ensino e a aprendizagem em tempos pandêmicos}

Deve-se destacar que o ensino remoto emergencial (ERE) e o ensino à distância (EAD) não podem ser compreendidos como sinônimos. Tal equívoco pode ser notado em informações compartilhadas em diferentes ambientes, em especial nas redes sociais on-line. O termo "remoto" significa distante no espaço e se refere a um distanciamento geográfico. Designa-se o ensino dentro dessa modalidade, pois os docentes e os estudantes estão impedidos, por força de decreto, a 
frequentarem instituições educacionais, seguindo a regra de não gerar aglomerações. Caracterizase como emergencial, pois o planejamento pedagógico elaborado para ano letivo de 2020 teve que, de forma abrupta, ser colocado em hold até que a situação pandêmica seja remediada (BEHAR, 2020).

No ensino ERE dois tipos de atividades são desenvolvidas, as síncronas e as assíncronas. As síncronas ocorrem seguindo os moldes do ensino presencial, mas com todos agora conectados virtualmente, um formato "estamos juntos, mas cada um na sua casa". As atividades assíncronas, no entanto, não requerem a presença simultânea, o docente pode propor dada atividade e o estudante a realizar no momento que julgar mais adequado dentro do prazo estipulado, garantindo maior flexibilidade e exigindo disciplina do discente.

O ensino à distância se configura como uma modalidade educacional, na qual a mediação didático-pedagógica nos processos de ensino e aprendizagem ocorre com a utilização de meios e tecnologias de informação e comunicação, com estudantes, tutores e docentes trabalhando em atividades educativas, a partir de lugares ou tempos diversos. Ela possui um modo de funcionamento com uma concepção didático-pedagógica própria e abrange conteúdos, atividades e todo um design adequado às características das áreas dos conhecimentos gerais e específicos, contemplando o processo avaliativo discente (BEHAR, 2020).

Em linhas gerais, o ERE foi criado a partir de uma emergência, trata-se de uma adaptação para suprir uma necessidade pontual (não é possível estar fisicamente no mesmo espaço). O EAD não atende a esses moldes, pois trata-se de um formato construído e pensado para ser virtual desde os seus primórdios, por isso a característica “concepção didático-pedagógica própria”.

As abordagens, os métodos e as técnicas utilizadas e consolidadas na educação tradicional estão sendo submetidas e passando por profundas e necessárias transformações em tempos de globalização da comunicação e informação, com surgimento das tecnologias oriundas da internet num passado recente, surgindo novas alternativas e possibilidades para oferta e consumo dos processos de ensino e aprendizagem. Nesse novo cenário de alternativas para ensinar e aprender, apesar dos percalços, sabe-se que formatos não-presenciais se apresentam como um dos caminhos.

A sociedade em tempos de pandemia tem sido desafiada a aderir ao ensino remoto e ao ensino a distância como alternativas para o prosseguimento das atividades educacionais, cumprimento dos calendários escolares, gerindo os processos de ensino e de aprendizagem, sem colocar em risco a saúde da comunidade envolvida.

Todo um sistema, na sua maioria fundado na presença física, movimenta-se a fim de criar e aperfeiçoar ferramentas e soluções para atender as demandas do ensino. Diante de um cenário 
de incertezas e desigualdades que tem provocado reflexões sobre como se adaptar e minimizar impactos negativos, as perguntas são muitas e as respostas insuficientes.

O mundo e a educação definitivamente não serão os mesmos pós pandemia. O ERE e o EAD se mostram como uma realidade, que pode caminhar como alternativa ou fazer parte da educação tradicional. Para tanto, são necessárias novas posturas no que tange aos investimentos no campo da infraestrutura e da qualificação profissional para atender as demandas atuais pois,

a pandemia de covid-19 forçou instituições educacionais em todo o mundo a utilizar
repentinamente ferramentas tecnológicas disponíveis há muito tempo para criar
conteúdo experiências de aprendizado remoto para estudantes. Educadores de todas as
áreas estão experimentando novas possibilidades de ensinar - e isso é um grande avanço
para um dos setores mais resistentes a mudanças e a adoção de novas tecnologias
(HERRERA, 2020, [s.p.])

Assim, as ferramentas tecnológicas capazes de propiciar formas de ensino para além do presencial existem há certo tempo. Contudo, a falta de investimento nessa área forçou que todo um sistema posto fosse paralisado e alterado em poucos meses. Tal alteração não indica, porém, a instalação de um sistema funcional em todos os seus aspectos. Vive-se um momento de tentativas, em que os resultados estão sendo analisados de forma parcial.

Na educação tradicional, Costa (2020) afirma que durante muito tempo a melhor fonte de informações era o docente, mas com as novas tecnologias, o estudante tem muitos conhecimentos ao seu dispor e o docente deixou de ser o detentor do saber, passando a mediador do conhecimento.

$\mathrm{Na}$ era das tecnologias da informação e comunicação, quando se pensa em recursos de apoio ao processo de ensino e de aprendizagem, tanto para o docente que planeja e executa as suas aulas, quanto para o estudante, torna-se importante observar que modelos tradicionais como a biblioteca, o livro, a sala nos seus formatos físicos e, ainda, a definição de horários para encontros presenciais de estudos, em grande parte vem sendo aos poucos substituído ou alternado com formas mais flexível. Como alternativa ao formato físico, tem-se o digital, que a partir de um dispositivo como o celular ou o computador torna possível o acesso a toda essa estrutura de recursos e rotina. Tal abordagem pode estar acessível e ao alcance de quase todos e esse "quase" delineia um dos maiores desafios nesse contexto: a desigualdade de acesso.

No campo dos desafios e das dificuldades que existem para o estudante do ensino não presencial, pode-se destacar fatores como o não desenvolvimento de uma cultura ligada à autonomia e à autodisciplina. Tais características são essenciais para estudar à distância, pois o estudante se torna o principal ator e responsável pela construção do seu próprio conhecimento. Ainda que no ensino presencial o estudante tenha que realizar as suas atividades antes ou após as 
ações presenciais em sala, campo, laboratório, dentre outros locais, a autonomia se impõe de forma mais acentuada no formato não presencial físico. Martins e Almeida destacam, ainda, outros aspectos:

Vídeos, conferências on-line, mensagens, lives, áudios, imagens e sons, tudo junto e
misturado. Docentes, estudantes e seus responsáveis, criando em tempo recorde táticas
de sobrevivência a uma demanda de ensino, muitas vezes massivo e unidirecional, o
chamado ensino remoto. Esse frenesi do ensino remoto que está sendo praticado, no
nosso ponto de vista, equivocadamente por muitas escolas hoje em nosso país não é um
problema do COVID-19. É problema de como muitos de nós temos entendido e
praticado o funcionamento das escolas há bastante tempo. Observamos como demanda
primordial nessas propostas remotas o foco no conteúdo a ser transmitido, com a
gravação de videoaulas e envio de apostilas. Esse fato nos oferece pistas importantes
sobre mudanças necessárias na educação brasileira. (MARTINS; ALMEIDA, 2020, p.
219)

Desse modo, os desafios e os problemas vão além da capacidade de ser disciplinado para estudar ou ter acesso às informações. O desafio do ensino pode estar justamente no foco que se elegeu, o qual não dá conta de todo o contexto necessário a um aprendizado real. Deve-se considerar, também, a forma como cada docente e estudante encaram e utilizam esse formato. Para tanto,

\begin{abstract}
a preparação de toda a comunidade escolar para a inclusão da tecnologia não se faz do dia para a noite. Investir na formação de docentes é uma boa opção para iniciar uma efetiva transformação, valorizando esses atores importantíssimos. Precisamos pensar na educação como um todo, em que não haja um único protagonista (o conteúdo, por exemplo). Acreditamos num processo em rede, em que cada ator (o que age) possa também ser autor (o que cria) em determinado momento. Isso deve valer para todos que são importantes num processo de educação on-line: o estudante, o docente, o material didático, a ambiência formativa proposta pelo mediador, o ambiente virtual de aprendizagem, entre outros, de forma a integrar em rede para a construção do conhecimento (MARTINS; ALMEIDA, 2020, p. 221).
\end{abstract}

Além disso, o acesso à informação e ao ensino se tornou um dos maiores limitadores. Muitos estudantes podem até possuir celular, mas isso não significa acesso de qualidade às aulas disponibilizadas. Muitos são os relatos compartilhados pela internet de estudantes que não têm como custear o acesso à internet, ou comem ou pagam a internet. Outros até possuem acesso via dados móveis, mas não conseguem manter a conexão com qualidade, o que afeta diretamente na motivação em continuar participando e na compreensão do assunto em discussão.

Quanto aos benefícios do ensino não presencial, em especial durante a pandemia, faz-se mister considerar que o ensino sem a presença física, ao ser adotado pelas instituições desenvolve muitos papéis, dentre eles, o despertar de possibilidades e oportunidades para aprender e para ensinar de forma diferente do que vinha sendo praticado. Docentes se tornaram estudantes, estudantes se tornaram docentes e vice versa, em um processo de contínuo ensino e de aprendizagem que se aplica em ambos os papéis. 
Apesar de reconhecer tais possibilidades, a que custo tudo isso ocorrerá também deve ser analisado. Como asseverou Martins e Almeida (2020), uma mudança tão profunda não se faz da noite para o dia. Os docentes precisam de uma formação sólida para ensinar, os estudantes precisam aprender a aprender nesses formatos mais dinâmicos (virtual). A valorização dos profissionais que se viram obrigados a encarar esse processo se traduz como essencial, pois a casa do docente se tornou salas de aula, a sua internet, energia elétrica, mobiliário, tudo passou a ser compartilhado com os seus "consumidores", contudo, custeado pelo professor.

\section{A UNEMAT em meio à pandemia}

Nessa caminhada em busca de respostas à crise pandêmica e acadêmica, a UNEMAT criou duas resoluções para direcionar as atividades do ERE, a Resolução no 028/2020 (UNEMAT, 2020a) e a no 029/2020 (UNEMAT, 2020b). A resolução nº 028/2020 do CONEPE regulamenta a oferta de componentes curriculares pela tecnologia de informação e comunicação, meios digitais e demais modalidades remotas, de forma emergencial, mantida a centralidade da relação entre docente e discente, enquanto durar a situação de pandemia do novo Coronavírus (Covid-19). Nesse documento, destaca-se a centralidade da relação docente e discente e se indica que as atividades letivas farão uso de diferentes tecnologias informação e comunicação, meios digitais e demais modalidades remotas. Os componentes curriculares cursados no formato ERE poderão ser integralizados como presenciais. A resolução destaca, ainda, o trabalho em conjunto que deve ser realizado pelas faculdades e cursos, a fim de operacionalizar o proposto.

Como exatamente serão as aulas na graduação? A resolução n ${ }^{\circ}$ 029/2020 versa sobre esse assunto. O semestre que antes era formado por um bloco, em termos de tempo, foi dividido em três blocos, denominados período letivo suplementar excepcional (PLSE), mudando o formato do semestre para três ciclos de seis semanas cada. Cada docente deverá ofertar uma disciplina por PLSE, de forma individual ou em dupla. Será facultado ao discente se matricular em cada PLSE. Caso não se matricule, fica assegurada ao estudante a possibilidade de término do semestre 2020/1 a partir de onde parou, quando as atividades presenciais físicas forem restabelecidas. Caso ocorra a reprovação em componentes curriculares parte do PLSE, essa não será registrada no histórico escolar.

Uma questão, porém, põe em risco todo esse planejamento: o acesso contínuo e de qualidade ao ensino. Sabe-se que existe uma parte significativa da população que não possui acesso à internet ou aos equipamentos que permitam essa relação virtual com a universidade. A inclusão digital em meio a todo esse emaranhado de dificuldades e possibilidades se apresenta como uma 
das questões mais desafiadoras, pois o planejamento pode ser elaborado e apresentado como algo adequado, contudo, se na sua efetivação não garantir o acesso de forma igualitária, as desigualdades se tornarão ainda maiores. A pandemia expõe, assim, mais uma face das desigualdades brasileiras,

O Comitê Gestor da Internet no Brasil (CGI.br) revelou em uma pesquisa divulgada em 2019 que 58\% dos domićlíios no Brasil não têm acesso a computadores e 33\% não dispõem de internet. Os dados apontam ainda que, nas áreas rurais, 43\% das escolas não têm acesso à internet. Além disso, a desigualdade no acesso à rede é ainda maior nas classes mais baixas (OXFAM, 2020).

Diante desse desafio, a resolução $n^{\circ}$ 028/2020 indica a criação de uma política de inclusão digital, a fim de diminuir as desigualdades e de garantir ao maior número de discente o acesso e a qualidade de ensino no formato remoto. O edital n ${ }^{\circ}$ 002/2020 da UNEMAT foi lançado em 22 de julho e tem como objetivo apoiar a participação dos estudantes de graduação da instituição nas atividades de ensino remoto de componentes curriculares ofertados pelo PLSE, pela concessão do auxílio inclusão digital (UNEMAT, 2020c). O auxílio inclusão digital poderá ser concedido aos estudantes com matrícula ativa em 2020/1, regularmente matriculados no PLSE e que se encontrarem em situação de vulnerabilidade socioeconômica, devendo apontar na inscrição a dificuldade de acesso digital às atividades do ensino remoto, por falta de recursos financeiros para a contratação de serviço de internet.

No edital em questão são considerados vulneráveis socioeconomicamente os estudantes com renda per capita de até um salário mínimo e meio. Contudo, tal documento não define a partir de que universo essa renda se refere, se per capita em nível nacional, estadual, municipal ou familiar. Esta pesquisa abordou tal aspecto pela vertente de renda familiar, o que, de forma direta, não possibilita comparações com o formato do edital em questão. Ainda assim, são permitidas algumas formas de análise. Quando questionados sobre a renda familiar, 9,1\% vivem com menos que 1 salário mínimo; 24,8\% com 1 salário mínimo; 46,1\% indicaram ter uma renda que varia entre 2 a 3 salários mínimos; $13 \%$ com 4 a 5 salários mínimos; 3,3\% com 6 a 7 salários mínimos; 1,4\% com 8 a 9 salários mínimos e 2,3\% acima de 10 salários.

A partir desses dados, nota-se que desses, aproximadamente 33,9\% terão direito ao auxílio, pois considerando a renda familiar estão automaticamente abaixo da renda per capita de até um salário mínimo e meio estipulado no edital. Dos respondentes, 53,5\% têm a família como responsável financeiro, $19,5 \%$ dos respondentes são responsáveis pelo seu sustento, 25\% destacam que assume em conjunto com a família o seu sustento e $2 \%$ indicaram a opção “outros”.

O quantitativo de auxílios ofertados se dará conforme a disponibilidade financeira e orçamentária da instituição. Os acadêmicos receberão em forma de doação um semicondutor 
(chip), com capacidade de tráfego de informações de até 10 (dez) gigabytes renovados mensalmente até dezembro de 2020. Os estudantes deverão inscrever-se exclusivamente on-line e apresentar documentação requerida, a fim de receber o auxílio.

Trata-se de uma iniciativa que visa ofertar internet, não abarcando, no entanto, outras limitações, como equipamentos necessários ao acesso. Será que os acadêmicos em situação de vulnerabilidade econômica possuem computadores, celulares ou outros equipamentos que permitam acessar as aulas com qualidade? Em termos de fornecimento do serviço de internet, como isso funciona em Nova Xavantina? Ter um chip com gigabytes de internet liberados não significa que o acesso será efetivado com qualidade.

Nesse contexto, um olhar ainda mais aprofundado e específico para cada câmpus da UNEMAT talvez seja requerido, já que seus 13 câmpus se encontram localizados em municípios onde os sinais de internet móvel se apresentam de forma diferenciada, em termos de qualidade. Há que se considerar, também, que o movimento é intenso em busca de respostas para as questões do momento e nem tudo é passível de solução imediata. Nota-se, assim, os esforços empreendidos e a indicação da contínua busca por soluções por parte da universidade.

Em relação ao trabalho administrativo, a UNEMAT adotou o formato teletrabalho, com presença física esporádica no câmpus para a resolução de questões pontuais e impossíveis de serem resolvidas via e-mail, telefone, Whats $A$ pp ou outras ferramentas. Os trabalhadores do grupo de risco realizam as suas tarefas estritamente via teletrabalho.

Alguns projetos de pesquisa e extensão estão ocorrendo durante esse período, inclusive com processo de análise de propostas otimizados, muitos com foco no objeto pandemia. Alguns possuem caráter social, buscando, por exemplo, beneficiar estudantes que estejam passando necessidades alimentícias nesse momento, um exemplo disso é o projeto de extensão Rede Solidária, em desenvolvimento no câmpus UNEMAT Nova Xavantina.

Ações como essa vêm ao encontro de algo esperado e confirmado no presente estudo - as dificuldades financeiras causadas pela pandemia. Dos 492 respondentes, 124 indicam estar passando por dificuldades financeiras ligadas à perda de emprego ou "bicos" e a partir desses fatores começam as dificuldades em manter elementos básicos, como alimentação e moradia. O setor de serviços, por exemplo, responsável por significativa parcela dos trabalhos formais e informais do país, registrou queda recorde em abril de 2020, impactando de forma profundamente a vida das pessoas (G1 ECONOMIA, 2020). Na sua maioria, tanto estudantes como os seus familiares faziam parte desse setor. 
CALDEIRA, Regiane; SUDRÉ, Stephanni G. Silva; PEREIRA, Gabriel José. Entre as conexões e as desconexões: experiências acadêmicas em tempos de distanciamento social físico

\section{A comunicação e o acesso ao ensino}

Com a Portaria n 343 de 17 de março de 2020, o Ministério da Educação (MEC) determinou "a substituição das aulas presenciais por aulas em meios digitais, enquanto durar a situação de pandemia da COVID-19”" (BRASIL, 2020, p. 1). Tal aspecto ampliou a necessidade de compreender o acesso à informação e o uso dos recursos virtuais nos ambientes educacionais, no presente caso, o ambiente universitário.

Dos entrevistados, $87 \%$ indicam possuir computador e 13\% deles não possuem o equipamento. Nesse contexto, outro equipamento poderá ser utilizado, o celular, visto que 99,4\% dos entrevistados relataram possuir e $0,6 \%$ indicaram não possuir. Porém, deve-se questionar para quais fins cada equipamento pode ser empregado com qualidade. O celular, por exemplo, pode servir para assistir aulas on-line, participar de eventos online, fazer comentários, responder questionários rápidos, dentre outras ações, mas e quando a atividade requer longas leituras, escrita de textos mais avolumados, como seria utilizar o celular? Os estudantes de engenharia por exemplo, que precisam de programas específicos para realizar certas atividades, teriam significativa dificuldade para executar tais tarefas em um celular.

O fato de possuir equipamentos pode, ainda, não significar o acesso ao ambiente virtual de qualidade, pois foi observado que 61,8\% têm internet a cabo, 11,6\% usam a internet móvel e 26,6\% deles usam ambas as formas de acesso à internet. Os estudantes possuem computador e preferem se comunicar pelo Whats $A p p$ e a dificuldade maior encontrada pode estar no acesso à internet. Essas dificuldades são identificadas como desafio de manter o foco na disciplina com os estudos, seguida por sinal da internet ruim e outra parte por não conseguir entender as informações disponibilizadas.

Observou-se que 61,8\% dos estudantes preferem o ensino presencial, 34,3\% menciona preferir uma mescla entre o ensino presencial e o não presencial. A preferência pelo ensino não presencial se apresentou em 3,9\% dos entrevistados. Tais indicativos demonstram o enraizamento no formato presencial, mas com significativa tendência ao não presencial, o que, de certa forma, vem se desenvolvendo ainda que de forma tímida no ambiente universitário. $\mathrm{Na}$ UNEMAT, por exemplo, estabeleceu-se um plano de reestruturação dos projetos pedagógicos para o primeiro semestre de 2020, incluindo a possibilidade de oferta de parte da carga horária do curso de forma não presencial, conforme portaria no 2.117 de 06 dezembro de 2019 do MEC (BRASIL, 2019).

Quanto às atividades estudantis on-line, 65,7\% dos acadêmicos indicaram possuir algum curso realizado online e 34,3\% não tiveram essa experiência, reforçando os desafios institucionais já mencionados e revelando os desafios metodológicos. As experiências foram classificadas como boa em $37,6 \%$, ótima em $24,3 \%$, regular em $23,7 \%$, ruim $7,4 \%$, péssima $5 \%$ e a opção outra $2 \%$. 
Isso, por sua vez, demonstra um diálogo, ainda que tímido, entre o público e outros formatos de ensino e de aprendizagem, que não o presencial físico.

Verificou-se que aproximadamente $60 \%$ dos estudantes já realizaram algum curso on-line e estão inseridos em alguma rede social, como: Instagram, Facebook ou Whats App. Esse índice de acesso à informação via redes sociais é animador, contudo, há que se considerar que do total matriculado o universo respondente corresponde a aproximadamente $41 \%$ da população estudada. Isso pode indicar, dentre muitas razões, que os não participantes podem estar sem acesso à internet, sem equipamentos para acesso, falta de conhecimento em relação ao uso dessas tecnologias ou, ainda, tendo dificuldades com todos esses aspectos. Deve-se considerar, também, o desinteresse em participar de atividades como essa. A falta de conhecimento em relação ao uso das tecnologias limita o acesso à informação e à formação.

Em relação às dificuldades ligadas ao ensino não presencial, $52 \%$ dos estudantes indicaram ter dificuldades. Dentre elas, as mais recorrentes são a falta de foco e disciplina com os estudos em 68\% dos entrevistados, a compreensão das informações em 44,7\% deles, o sinal de internet ruim em $47 \%$, não tem equipamento em $15,4 \%$ dos entrevistados e $2,3 \%$ não tem internet.

Durante a pandemia, 78,3\% dos estudantes entrevistados continuaram ou aprofundaram, de forma independente, os estudos referentes às disciplinas que estavam cursando na universidade e 21,7\% não deram continuidade. 63,4\% estão cursando ou já cursaram atividades educacionais online durante o período de paralisação. Isso pode indicar uma proximidade com as ferramentas remotas e pode ajudar na retomada das aulas. Muitas atividades de ensino estão utilizando ferramentas como as redes sociais. Docentes estão adotando lives, web-conferências e grupos no Whats $A p p$, a fim de gerar aproximação, interação e compartilhar conhecimentos.

Quando questionados sobre as suas preferências em termos de compartilhamento de materiais para estudo, 7,1\% dos acadêmicos indicaram preferir que os docentes repassem por escrito, $13 \%$ via ambiente virtual, $17,1 \%$ por slides com imagens ilustrativas e $62,8 \%$ preferem uma mescla de todas essas opções. Essas informações demonstram que os acadêmicos preferem um ambiente dinâmico, com opções variadas, que possam estimular diferentes formas de ensino e aprendizagem. A oferta não presencial de parte da carga horária de algumas disciplinas do curso de graduação dos entrevistados foi vista por 50,6\% como algo positivo, 31,5\% não sabem dizer e $17,9 \%$ deles acham algo negativo. 
CALDEIRA, Regiane; SUDRÉ, Stephanni G. Silva; PEREIRA, Gabriel José. Entre as conexões e as desconexões: experiências acadêmicas em tempos de distanciamento social físico

\section{Considerações finais}

Com a pandemia, o planejamento ligado ao ensino superior em formato presencial teve que ser revisto quase na sua totalidade. Adaptações ao formato enraizado na presença foram redesenhadas. Os sujeitos parte desse processo tiveram que, rapidamente, mudar as suas formas de aprender e compartilhar saberes. O olhar, antes bastante cético em termos de ensinar via uma tela, foi, em muitos casos, obrigatoriamente deixado de lado.

Assim, uma nova paisagem se fez no ambiente universitário. Não há mais aglomerações na cantina, nem salas cheias de estudantes, não se ouve mais as conversas pelos corredores, nem o movimento dos carros, bicicletas e passos pelos acessos do câmpus. Hoje, o câmpus repousa, ou melhor, parte da sua estrutura física, pois docentes, técnicos e outros colaboradores se desdobram para tentar aprender a viver nesse novo normal. As resistências tiveram que ser vencidas e agora, cada um na sua casa, busca-se, de alguma forma, cumprir as suas tarefas - uns a de ensinar, tendo que passar por longos treinamentos online, outros a de aprender e ter desempenho satisfatório.

Contudo, é comum a todos uma certa insegurança no que se refere aos resultados de tudo isso. Os estudantes do câmpus de Nova Xavantina passaram a aprofundar os seus conhecimentos por ferramentas que antes eram parte da comunicação cotidiana - as redes sociais. A instituição criou formas de chegar até os acadêmicos via sistema que sustentasse o formato emergencial e que pudesse dar continuidade a esse formato de ensino mesmo após a pandemia, o Sigaa. Os docentes da noite para o dia estão tendo que se desdobrar e conhecer formas que, para muitos, são novas em termos de ensino.

Configurou-se um movimento bastante intenso, tudo girando ao redor da educação, na busca por minimamente ofertar um ensino de qualidade. Contudo, nem tudo sai como no papel, hoje se pode dizer, que nem tudo sai como planejado na tela. O sistema ainda apresenta falhas no seu funcionamento e os docentes têm muitas dificuldades para aprender tanto em tão pouco tempo, a fim de então compartilhar. Os estudantes, apesar da desenvoltura em termos de tecnologias, sentem-se confusos, inseguros quanto à sua capacidade de processar tudo isso. Não se pode negar os avanços impulsionados pela pandemia no campo da educação, mas não se pode desconsiderar muito menos, os impactos que esses avanços podem causar na vida daqueles que não conseguiram, por diversas razões, participar desse movimento de adaptação, que pode, de maneira considerável, fazer parte do cotidiano universitário de forma permanente. 
CALDEIRA, Regiane; SUDRÉ, Stephanni G. Silva; PEREIRA, Gabriel José. Entre as conexões e as desconexões: experiências acadêmicas em tempos de distanciamento social físico

\section{Referências}

BRASIL. Portaria $n^{\circ} 2.117$, de 06 dezembro de 2019. 2019. Oferta de carga horária na modalidade Ensino à Distância-EAD. Diário Oficial da União: edição 239, seção 1, Brasília, DF, p.131, 11 dez. 2019. Disponível em: https://www.in.gov.br/en/web/dou/-/portaria-n-2.117-de-6-dedezembro-de-2019-

232670913\#: :text=1\%C2\%BA\%20Esta \%20Portaria $\% 20$ disp $\%$ C3\%B5e $\% 20$ sobre,da $\% 20$ legisla $\% \mathrm{C} 3 \% \mathrm{~A} 7 \% \mathrm{C} 3 \% \mathrm{~A} 30 \% 20$ educacional $\% 20 \mathrm{em} \% 20$ vigor. Acesso em: 23 nov. 2020.

BRASIL. Proposta de parecer sobre reorganização dos calendários escolares e realização de atividades pedagógicas não presenciais durante o periodo de pandemia da covid-19. Conselho Nacional de Educação. 2020. Ministério da Educação: Brasília. Disponível em: http:/ / portal.mec.gov.br/index.php?option=com_docman\&view $=$ download\&alias $=144511$ texto-referencia-reorganizacao-dos-calendarios-escolares-pandemia-da-covid19\&category_slug=marco-2020-pdf\&Itemid=30192. Acesso em: 01 jul. 2020.

BEHAR, A. P. O ensino remoto emergencial e a educação à distância. Jornal da UniversidadeUFRGS. 2020. Disponível em: https://www.ufrgs.br/coronavirus/base/artigo-o-ensino-remotoemergencial-e-a-educacao-a-distancia/. Acesso em: 19 jul. 2020.

COSTA, E. L. Ensino tradicional. 2020. Disponível em:

https://www.portaleducacao.com.br/conteudo/artigos/biologia/ensino-tradicional/11345. Acesso em: 31 jul. 2020

G1 ECONOMIA. Com pandemia, setor de serviços tem queda recorde de 11,7\% em abril. 2020. Disponível em: https://g1.globo.com/economia/noticia/2020/06/17/setor-de-servicos-tem-queda-recordede-117percent-em-abril-diz-ibge.ghtml. Acesso em: 19 jul. 2020.

HERRERA, L. A pandemia do coronavirus pode mudar para sempre a educação. 2020. Disponível em: https://epocanegocios.globo.com/colunas/noticia/2020/04/pandemia-do-coronavirus-podemudar-para-sempre-educacao.html. Acesso em: 31 jul. 2020.

MARTINS, V.; ALMEIDA, J. Educação em tempos de pandemia no Brasil: saberesfazeres escolares em exposição nas redes e a educação on-line como perspectiva. Docência e cibercultura,v. 4, n. 2, p. 215-224, mês abreviado 2020.

OXFAM. Como o coronavirus afeta a educação no Brasil? 2020. Disponível em: https://www.oxfam.org.br/blog/como-o-coronavirus-afeta-a-educacao-no-brasil/. Acesso em: 30 jul. 2020.

UNEMAT. Resolução 028/2020 - CONEPE. Cáceres: Universidade do Estado de Mato Grosso, 2020a. Disponível em:

http://www.UNEMAT.br/resolucoes/resolucoes/conepe/4327_res_conepe_28_2020.pdf. Acesso em: 20 jul. 2020.

UNEMAT. Resolução 029/2020 - CONEPE. Cáceres: Universidade do Estado de Mato Grosso, 2020b. Disponível em:

http://www.UNEMAT.br/resolucoes/resolucoes/conepe/4326_res_conepe_29_2020.pdf.

Acesso em: 20 jul. 2020. 


\section{Dialogia}

CALDEIRA, Regiane; SUDRÉ, Stephanni G. Silva; PEREIRA, Gabriel José. Entre as conexões e as desconexões: experiências acadêmicas em tempos de distanciamento social físico

UNEMAT. Edital 002/220 UNEMAT/PRAE de seleção para concessão de auxílio. Cáceres: Universidade do Estado de Mato Grosso, 2020c. Disponível em: http://portal.UNEMAT.br/media/files/Edital_002_2020_AUXILIO_DIGITAL_PRAE_UNE MAT.pdf. Acesso em: 20 jul. 2020.

Recebido em: 20 set. 2020/ Aprovado em: 26 nov. 2020

Cite como

(ABNT NBR 6023:2018)

CALDEIRA, Regiane; SUDRÉ, Stephanni G. Silva; PEREIRA, Gabriel José. Entre as conexões e as desconexões: experiências acadêmicas em tempos de distanciamento social físico. Dialogia, São Paulo, n. 36, p. 162-175, set./dez. 2020. Disponível em: https://doi.org/10.5585/dialogia.n36.18294.

\section{American Psychological Association (APA)}

Caldeira, R., Sudré, S. G. S., \& Pereira, G. J. (2020, set./dez.). Entre as conexões e as desconexões: experiências acadêmicas em tempos de distanciamento social físico. Dialogia, São Paulo, 36, p. 162-175. https://doi.org/10.5585/dialogia.n36.18294. 